\title{
La difusión del patrimonio histórico cultural de las casas-museo a través de los servicios ofertados por sus centros de documentación
}

\author{
Yolanda Martín González \\ Ana Belén Ríos Hilario \\ Universidad de Salamanca (España)
}

\section{Resumen}

Se analiza el papel que juegan las casas-museo castellano-leonesas en la difusión del patrimonio histórico cultural que albergan. Estas instituciones salvaguardan la memoria de algún personaje ilustre o vinculado de manera especial a la localidad donde se ubican, y suelen atesorar un valioso fondo documental reunido con frecuencia por el homenajeado. Partiendo de la información disponible en la red, bibliográfica y recogida in situ, se realiza una valoración de las distintas actividades que desarrollan y que se pueden resumir del siguiente modo: servicios y actividades típicamente museísticos — exposiciones, conferencias, etc. - ; servicios propiamente documentales; fondos - constituidos, por lo general, por el legado bibliográfico de la personalidad; publicaciones propias; congresos y asambleas celebradas sobre distintos aspectos pero siempre con un eje común que es el propio homenajeado, y servicios de apoyo a la investigación.

Palabras claves: Casas-museo. Servicios de información. Patrimonio histórico cultural. Castilla y León.

\section{Abstract}

The role of house museums in the dissemination of cultural heritage in Castilla-León (Spain) is discussed. These institutions keep the memory, documents and artifacts of an important personage of a locality. Based on bibliography, Internet sources and on site visits, their main services are analyzed: exhibitions, conferences, collections, publications, and research facilities.

Keywords: House-museums. Information services. Cultural and Historical Heritage. Castilla-León (Spain). 


\section{Introducción}

La imagen que popularmente se suele tener de las casas-museo no es muy acertada en general. O bien se las considera como un museo un poco anticuado, ensimismado en la evocación romántica del autor, o se las considera una institución de contenidos y funciones eruditas solo al alcance de los especialistas.

De un tiempo a esta parte las cosas han cambiado. Las casas-museo, sin perder del todo su condición inicial, han abierto sus puertas a la sociedad y le muestran sus contenidos y, sobre todo, los significados culturales de la memoria del autor; han modernizado sus instalaciones museísticas y salen al encuentro de la gente con actividades y publicaciones; han actualizado sus métodos de gestión de bibliotecas y archivos y desempolvan documentos desconocidos o poco valorados y los ofrecen a los estudiosos para ayudarles en la interpretación de la personalidad humana y literaria de los autores. Su naturaleza peculiar les hace diferenciarse de lo que son las instituciones museísticas más corrientes... Así, en contraste con lo que ocurre en los museos donde se genera y, por tanto, se gestiona un elevado volumen de documentación, en las casas-museo suelen ser más frecuentes fondos de otra naturaleza no bibliográfica pertenecientes al homenajeado. Igualmente, mientras que en los museos la documentación donde se detalla el origen y todos los pormenores relativos a las piezas es crucial para su justa valoración, en el caso de las casas-museo la información sobre su procedencia suele estar siempre clara.

En opinión de algunos estudiosos (Castrillo, 1999, p. 1), las casas-museo son consideradas por muchos como "lugares de conservación y esparcimiento más cercanos al almacén y la feria que a la actividad investigadora".

\section{Los servicios de información en el ámbito museístico}

Un museo es en sí mismo un sistema de información, ya que estos centros son por definición conjuntos organizados de documentos, siendo su misión principal la de coleccionar, documentar, mostrar e interpretar estos mismos. Como tal sistema de información le son aplicables todos los principios científicos y técnicos de la documentación.

A su vez, tales instituciones deben contar con centros de documentación o bibliotecas destinadas a "la colección de fondos documentales especializados, organizados para facilitar la adquisición, conservación, comunicación y presentación con fines de estudio, educación y deleite de los testimonios materiales que guarda un museo y apoyar las actividades propias del mismo" (López del Prado, 2003, p. 14). Partiendo de tal definición podemos afirmar que las funciones de las bibliotecas museísticas son las de difusión, educación e investigación y sus actividades estarán en concordancia con tales funciones, dedicándose con mayor 
esfuerzo a unas u otras según la finalidad que le otorgue el propio museo. Así, por ejemplo, si se concibe la biblioteca como un centro de investigación, entre los servicios que esta preste deberán primar los de referencia; si por el contrario su carácter es más de difusión se realizarán más actividades de extensión cultural.

Por otro lado, los fondos de los que debe nutrirse una biblioteca museística son difíciles de definir, al no tener claramente marcados los límites con el órgano del que depende. Podemos afirmar que influyen tres factores primordiales en la delimitación de tales recursos:

a) el grado de desarrollo técnico y orientación de la biblioteca;

b) las funciones que desempeña y servicios que presta;

c) la especialización del museo al que sirve.

Teniendo en cuenta estos principios, el resultado será que el centro de documentación del propio museo estará formado por "aquellos documentos textuales, sonoros, audiovisuales o iconográficos, en cualquier tipo de forma y soporte, cuyo contenido responda al área de interés del museo al que atiende y le sirva para alcanzar los objetivos y desempeñar las funciones que tiene asignadas tanto la biblioteca como el propio museo" (López del Prado, 2003, p. 22).

Finalmente, hablaremos del objetivo final de toda biblioteca: el usuario. En primer lugar, diremos que estará en relación con las propias funciones anteriormente definidas para este tipo de centros. Por otro lado, podemos realizar una división general entre lo que serían los usuarios internos y los usuarios externos. Como usuarios internos, evidentemente se incluiría al propio personal del museo, mientras que si hablamos del segundo rango, podemos citar a investigadores por cuenta propia (doctorandos, estudiantes universitarios, eruditos, etc.), e investigadores por cuenta ajena (como personal de casas de subastas, tasadores, etc.), entidades investigadoras (departamentos y organismos de investigación específicos), empresas particulares, o curiosos (personas que buscan un dato puntual sobre un asunto de orden particular). Resumiendo, estarían todas aquellas personas interesadas, directa o indirectamente, y con cualquier objetivo, en las materias cubiertas por la biblioteca.

\section{Tipología de los servicios que prestan las casas-museo en Castilla y León}

La selección de las casas-museo de Castilla y León se realizó a través de la página web dispuesta por la Excma. Junta de esta Comunidad, cuya dirección es www. turismocastillayleón. com.

De entre todas las posibilidades que se ofrecía en dicha página elegimos la opción "museo", en la que se englobaban indistintamente las diferentes tipologías 
de estos centros. Una vez realizada la búsqueda restringimos el estudio a las que figuraban literalmente como "casas-museo". El resultado final fue un listado de nueve casas-museo que aparecen descritas, junto con su ubicación y dirección electrónica, en la tabla I.

\begin{tabular}{llll}
\hline No $^{\circ}$ & Casa-museo & Ubicación & Web \\
\hline 1 & Blas Villadres & Burgo de Osma (Soria) & www. deblasvillodres. org \\
2 & Salaguti & Sasamón (Burgos) & No \\
3 & Antonio Machado & Segovia & No \\
4 & Miguel de Cervantes & Valladolid & No \\
5 & Cristobal Colón & Valladolid & www. fmcva. org/museos/index. htm \\
6 & Delhy Tejero & Toro (Zamora) & No \\
7 & Miguel de Unamuno & Salamanca & No \\
8 & José Zorrilla & Valladolid & www. fmcva. org/museos/index. htm \\
9 & General San Martín & Cervetos de la Cueza (Palencia) & No \\
\hline
\end{tabular}

Tabla I. Casas-museo en Castilla y León

Si nos fijamos detenidamente en la tabla I, podemos comprobar que es la capital de la comunidad la que presenta más centros de este tipo, concretamente 3. El resto de casas-museo se localizan en diversas zonas de Castilla y León, tanto en capitales de provincia (tal es el caso de Salamanca y Segovia) como en otras poblaciones (p. e. Burgo de Osma en Soria). Es significativo que solo tres de las nueve instituciones estudiadas cuenten con una página web como medio de difusión. Esto está en consonancia con lo que explicábamos anteriormente en la introducción, ya que este tipo de museos se encuentran en una fase de transición y adaptación a las modernas instalaciones museísticas.

Localizadas las distintas instituciones museísticas objeto de estudio, procedimos al análisis pormenorizado de las características propias de cada una ellas. Concretamente nos centramos en los siguientes apartados:

- Fondos: Se han incluido en este apartado tanto los recursos artísticos (obras pictóricas, gráficas, escultóricas, etc.) como los bio-bibliográficos (fotográficos, epistolarios, etc.).

- Documentos: Entendemos como tales los que permiten el estudio de la persona a la que se dedica la casa-museo, así como todo lo relacionado con su actividad profesional.

- Publicaciones: Este apartado englobaría las publicaciones realizadas por la propia institución y aquellas que facilitan el fomento de la edición de trabajos de investigación, en muchas ocasiones mediante la dotación de becas. 
- Actividades: Exposiciones temporales, congresos y eventos de carácter científico, presentaciones de libros, recitales y similares.

\begin{tabular}{clccc}
\hline $\mathrm{N}^{\circ}$ & \multicolumn{1}{c}{ Fondos } & Documentos & Publicaciones & Actividades \\
\hline 1 & Pictóricas y escultóricas & Sí & Sí & Sí \\
2 & Pictóricas y escultóricas & No & No & No \\
3 & Museísticos y bibliográficos & Sí & Sí & Sí \\
4 & Museísticos & Sí & No & No \\
5 & Museísticos y bibliográficos & Sí & Sí & No \\
6 & Artísticos & No & No & No \\
7 & Museísticos y biográficos & Sí & Sí & Sí \\
8 & Museísticos y biográficos & Sí & Sí & Sí \\
9 & Artísticos & No & No & No \\
\hline
\end{tabular}

Tabla II. Características de las casas-museo en Castilla y León

Si analizamos los datos extraídos de la tabla II, fijándonos en el apartado de los fondos que presentan las casas-museo, podemos comprobar que el tipo de fondo predominante es el museístico-bibliográfico. No es de extrañar, ya que la definición más generalizada de casa-museo suele ser la de aquella institución que presenta piezas y documentos de un determinado personaje generalmente literario. Otro tipo de fondos sería el artístico, y de modo más especifico el pictóricoescultórico, que presentan evidentemente las casas dedicadas a un determinado artista, como la de Blas Villadres o Delhy Tejero. Únicamente la casa de Miguel de Cervantes en Valladolid presenta objetos museísticos del propio homenajeado.

De las nueve casas-museo estudiadas, seis ofrecen distintos tipos documentales, entre los que se encuentran tanto los generados por el propio autor como los estudios realizados sobre el mismo. Además, y continuando con el estudio de esta tabla, cinco instituciones cuentan con sus propias publicaciones. Generalmente estos dos apartados están correlacionados, y los centros que presentan documentos suelen además realizar publicaciones. No se da, sin embargo, el caso contrario.

Finalmente, cuatro de estos centros realizan diversos tipos de actividades encuadradas dentro de lo que podríamos denominar de extensión cultural, como por ejemplo exposiciones, congresos, etc. Como conclusión a este apartado podemos decir que las casas-museo más completas, ya que presentan las cuatro categorías anteriormente definidas, son la de Blas Villadres, Antonio Machado, Miguel de Unamuno y José Zorrilla. Como se puede comprobar, estas tres últimas están dedicadas a ilustres escritores de la literatura española que generan un alto interés fundamentalmente desde el punto de vista de la investigación. 
Existen una serie de servicios que deberían ser estudiados de modo más detallado; sin embargo, dada la infrautilización de las nuevas tecnologías en estos ámbitos, nos ha sido imposible el desarrollo de tal información. No obstante, el examen detallado de la bibliografía impresa relativa al tema nos permite ofrecer una panorámica de otros elementos participantes en el sistema informativo que constituye todo museo. Entre ellos cabe destacar los siguientes:

- Colección: Entre el material que puede encontrarse en las bibliotecas de museos figuran monografías, publicaciones periódicas (vivas y muertas), manuscritos, discos, cintas magnetofónicas, microfilms, microfichas, cintas de casettes, grabados y separatas, planos, mapas y audiovisuales, CD-Rom y archivos de ordenador.

- Recuperación de la información: El catálogo constituye la herramienta de recuperación de información por excelencia. Casi todos los museos cuentan con catálogos de autores y obras anónimas; la mitad cuentan con catálogo de materias. La mayor parte no permiten el acceso automatizado a través del OPAC. En algunos casos se elaboran también inventarios, boletines de sumarios y novedades, desideratas, informes de recuentos, folletos informativos y guías de la biblioteca.

- Personal: Otro problema frecuente es el relacionado con el personal a cargo del servicio de documentación. En muchos casos estos profesionales suelen ser auxiliares administrativos y no cuentan con personal especializado.

- Servicios: Además de los mencionados anteriormente, algunas de estas entidades prestan los siguientes servicios: lectura en sala, orientación bibliográfica y reprografía, préstamo domiciliario, DSI e información remota.

- Usuarios: Entre los usuarios interiores y exteriores al museo podemos citar personal del centro, personal técnico de otros museos y profesores de universidad, miembros de asociaciones profesionales, opositores y doctores, profesores no universitarios, bibliotecarios y documentalistas. Dada la variedad tipológica es común denominar a este usuario con un término más general como es investigador.

- Aplicación de las nuevas tecnologías: Se observa una gran diferencia en el proceso de automatización en líneas generales entre el museo y la casa-museo. Por lo general, el primer tipo de centros se encuentran mucho más avanzados en este sentido, contando con una serie de aplicaciones informáticas que facilitan la gestión y difusión de su servicio. Por el contrario, escasas son aún las casas-museo que se sirven de las nuevas tecnologías para la divulgación de sus actividades, lo que limita el acercamiento del público a este patrimonio histórico-artístico. Pese a que, por lo común, se siguen utilizando soportes tradicionales para la difusión de obras como son las fotografías, los vídeos y la televisión, existe la excepción de la red creada por las casas-museo, dedicada 
a escritores españoles en la que a través de Internet se puede acceder a una aún limitada información al respecto.

\section{Conclusiones}

La principal conclusión a la que hemos llegado tras la realización de este estudio fue la sorpresa de encontrarnos en un principio con un bajo número de casas-museo existentes en esta comunidad autónoma, dada la riqueza patrimonial castellanoleonesa. Esto puede ser debido, en parte, a que no se encuentra muy bien definido el concepto de lo que debe ser una casa-museo, término que hemos pretendido definir a través de nuestro trabajo.

La situación en la que se hallan estas variantes museísticas dista mucho de lo que son los museos tradicionales. La razón de esta diferenciación puede deberse a la falta de recursos económicos y humanos, lo que supone un hándicap importante en el desarrollo de servicios y actividades que les den a conocer.

Hay un claro predominio de las casas denominadas de autor frente a las que podríamos denominar artísticas y etnográficas. Son pocas las que cuentan con centros de información específicos en los que se pueda tener acceso a un fondo bibliográfico especializado. En estos casos es frecuente que su gestión se realice a través de instituciones exteriores a la propia casa-museo. Tal es el caso de la Casa-Museo Miguel de Unamuno, vinculada a la Universidad de Salamanca.

Por otra parte, el uso de las aplicaciones multimedia todavía es algo muy alejado de la realidad de las casas-museo en nuestro país y que asusta a muchos profesionales que no entienden que este es un modo más activo de familiarizar al público en general con el arte y con la historia cultural de un pueblo.

En definitiva, podemos finalizar con la siguiente cita que representa la situación actual de las instituciones objeto de este estudio: "aquellos que, en algún momento, han sido - o son - usuarios de las bibliotecas de museos, coinciden en alabar la calidad de sus fondos; desgraciadamente también coinciden en lamentar la escasez de servicios y la cantidad de obstáculos que tuvieron que salvar para acceder a ellas" (Pacios Lozano, 1999; López de Prado, 1998, p. 1).

\section{Referencias}

Baena Alcántara, M. D. (1991). La accesibilidad del investigador al museo. Aspectos legales en la Comunidad Autónoma Andaluza. // Boletín de la ANABAD. (jul.-dic. 1991) 419-422.

Bellido Grant, M. L. (1999). Museos virtuales y digitales: nuevas estrategías de difusión artística. // Encuentro de Bibliotecas de Arte de España y Portugal. 7 (1999) 149-159.

Bonet Solves, V. E. (2000). El archivo familiar de la casa-museo Benlliure de Valencia. // Boletín de la ANABAD. 50:1 (2000) 9-20.

Scire. $11: 1$ (en.-jun. 2005) 187-194. ISSN 1135-3761. 
Cabrera Bonet, P. (1992). La investigación en los museos. // Política Científica. 34:11 (1992) 11-16.

Cacho, C.; Delclaux, L. (1992). Nuevas técnicas de documentación. // Política científica, 34:11 (1992) 38-41.

Castrillo Aguilera, L. (1999). El centro de documentación de un museo: una propuesta teórica // Encuentro de Bibliotecas de Arte de España y Portugal. 7 (1999) 39-48.

Castrillo Aguilera, L.; López de Prado, R. (1999). Las redes de bibliotecas de museo: una historia con futuro. // 65 IFLA Council and General Conference: Bangkok, Tailandia, Aug. 20-28, 1999. URL: <http://www.ifla.org/IV/ifla65/papers/017-157s.htm>. Consultado: 2004-06-20.

Gamboa Fuentes, S. R. (2000). Museo, museología y museografía. // Biblios. 2:5 (2000). URL:<http://redalyc.uaemex.mx/redalyc/pdf/161/16105306.pdf>. Consultado: 2004-06-20.

García Blanco, A. (1992). El museo como centro de investigación del público. // Política Científica. 34:11 (1992) 27-32.

García Caro, J. M.; Tejuelo, M. (2000). Panorama de los museos en Murcia. 1:1 (2000) 33-37.

Hernández Hernández, F. (1995). El documentalista de museos: una nueva profesión. // Revista General de Información y Documentación. 5:1 (1995) 83-96.

Hernández Hernández, F. (1992). Evolución del concepto de museo. // Revista General de Información y Documentación. 2:1 (1992) 85-97.

Hernández Hernández, F.; Agenjo Bullón, X. (1999). ¿Tres vías al conocimiento?: la información de archivos, bibliotecas y museos y el derecho de los ciudadanos a los documentos primarios. // Boletín de la ANABAD. 49:3-4 (1999) 559-568.

Hernández Hernández, F. (2000). Problemas de la museología como ciencia de la documentación. // I Congreso Universitario de Ciencias de la Documentación: Madrid, nov. 2000. Madrid . Universidad Complutense de Madrid, Servicio de Publicaciones. 1 (2000) 41-61.

López de Prado, M. R. (1998). Museos en Internet: análisis de los recursos documentales. // Jornadas Españolas de Documentación. 6 (1998) 495-514.

Luzón Nogué, J. M. (1991). La documentación en los museos. // Boletín de la ANABAD. (jul.-dic. 1997) 407-413.

Marty, P. F. (1999). Museum informatics and collaborative technologies: the emerging socio-technological dimension of Information Science in museum environments. // Journal of the American Society for Information Science. 50:12 (1999) 1083-1091.

Merlo Vega, J. A. (1999). Monográfico de Castilla y León: tierra despejada, tierra tranquila. // Educación y Biblioteca. 11 (1999) 101.

Palacios Lozano, A. R. (1999). Las bibliotecas de museos: situación actual y perspectivas de futuro. // Encuentro de Bibliotecas de Arte de España y Portugal. 7 (1999) 116-122.

Ramos Fajardo, C. (1999). El acceso a la información en los museos: ¿realidad o utopía? // Boletín de la ANABAD. 49:3-4 (1999) 735-442.

Sanguinetti,M.R. (2000). Marketing para Museos.//Biblios. 2:6(2000). URL: <http://www. geocities.com/emuseoros/Docs/marketing_museos.htm>. Consultado: 2004-06-20. 